\title{
Editorial
}

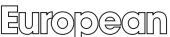

\section{The Beginning of a New Era}

After 12 years it is time for me to step down as co-editor-in-chief of European Addiction Research and move on to a new phase in my life. It has been a daring, fascinating and highly gratifying experience to set up and develop this journal. However, my decision is made easy by knowing that the drive and competence of Michael Krausz and Christian Haasen guarantee the continuation of our success story, and that the energy, vast experience and network of Wim van den Brink will be an invaluable new asset. 'Continuity' and 'excellence' are apt terms to describe this new editorial team. It will be my satisfaction to see the journal maintain and further strengthen its prominent position in a growing field of scientific addiction journals, and to give the new team my support whenever asked for.

When Michael Krausz asked me to join him in founding European Addiction Research, I was convinced that this was a timely and much-needed undertaking. The journal provided a forum that mirrored the cultural and political diversity across Europe and on other continents, giving a voice to groups and countries which, at that time, had little or no access to an international audience. The editorial strategy was also in line with the development of innovative and interdisciplinary approaches, which in turn triggered new responses to the growing challenges of the health-related and social problems that addictive behaviour gives rise to - as well as the resulting economic (and political) burden. Consequently, the journal was and is open to quality contributions from many different fields, including non-mainstream scientific domains. Another conceptual element also proved to be successful: the balanced mix of spontaneously submitted manuscripts and a special topic section with invited papers. It made the journal a source of information for those in need of overviews but also for researchers looking for new initiatives and aspects dealing with old or new problems. The next step might be systematic interdisciplinary reviews in order to satisfy the growing demand for clear perspectives in a diverse and often contradictory debate on conceptual, ethical and policy issues. These reviews could provide guidance for good practice, especially where public-health-related matters are concerned.

Now, my gratitude goes to Michael Krausz as the initiator and spiritus rector, to Christian Haasen for a highly efficient and sensitive management, to Karger Publishers - Thomas Karger and his house - for good collaboration and admirable professionalism, and of course to Wim van den Brink for his dedication and commitment. And special thanks are due to our readers and authors for their continued interest and stimulating support. My best wishes to you all. 